Provided for non-commercial research and education use. Not for reproduction, distribution or commercial use.

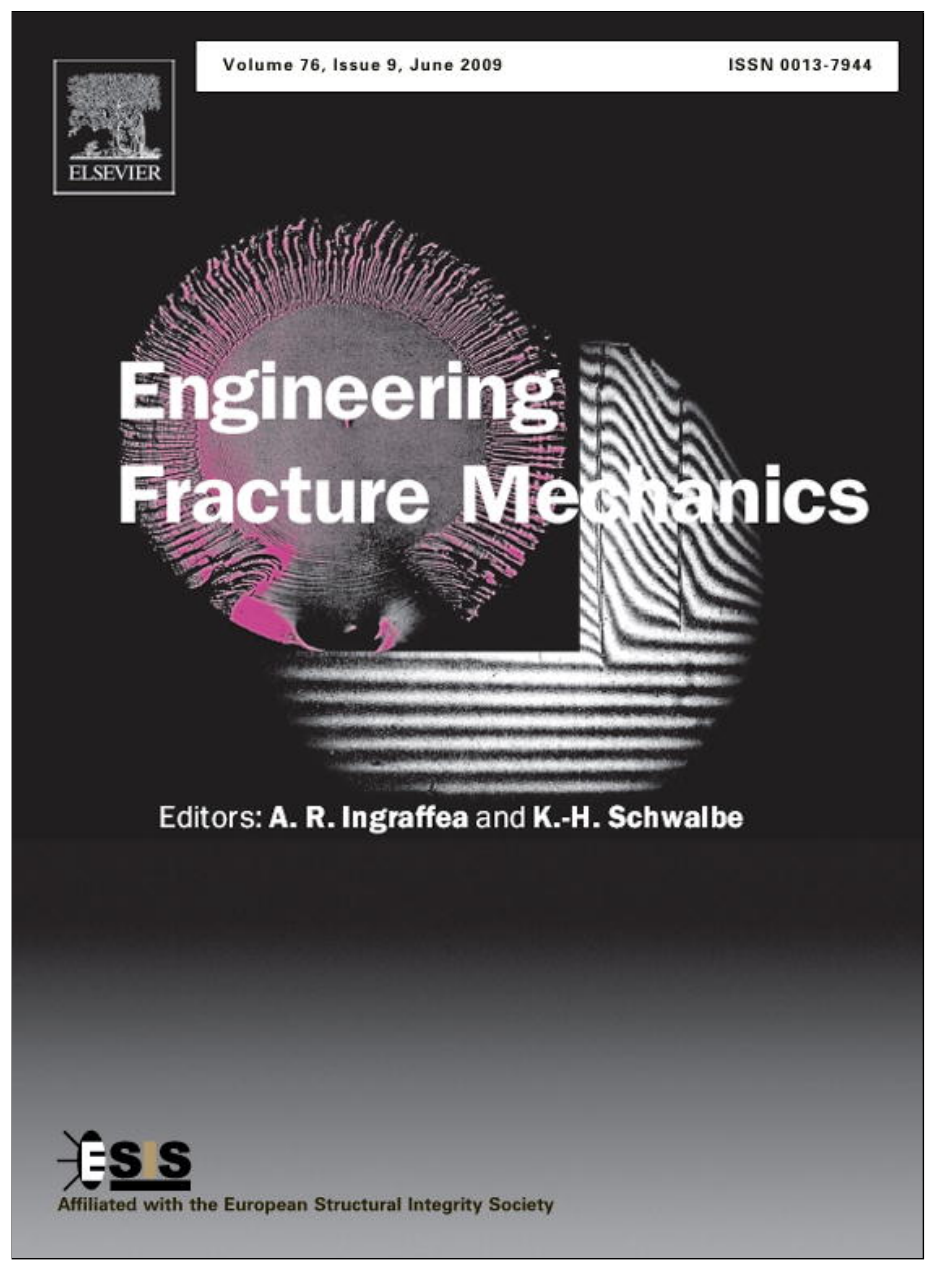

This article appeared in a journal published by Elsevier. The attached copy is furnished to the author for internal non-commercial research and education use, including for instruction at the authors institution and sharing with colleagues.

Other uses, including reproduction and distribution, or selling or licensing copies, or posting to personal, institutional or third party websites are prohibited.

In most cases authors are permitted to post their version of the article (e.g. in Word or Tex form) to their personal website or institutional repository. Authors requiring further information regarding Elsevier's archiving and manuscript policies are encouraged to visit:

http://www.elsevier.com/copyright 


\title{
Modelling fatigue crack propagation of a cracked metallic member reinforced by composite patches
}

\author{
Rong Wang ${ }^{\mathrm{a}, *}$, A. Nussbaumer ${ }^{\mathrm{b}}$ \\ a School of Materials Science and Engineering, Xi'an Shiyou University, 710065 Xi'an, China \\ ${ }^{\mathrm{b}}$ Swiss Federal Institute of Technology, EPFL, 1015 Lausanne, Switzerland
}

\section{A R T I C L E I N F O}

\section{Article history:}

Received 15 January 2008

Received in revised form 27 November 2008

Accepted 8 February 2009

Available online 15 February 2009

\section{Keywords:}

Cracked metallic member

Composite patch

Fatigue crack propagation

Fracture model

Fatigue life

\begin{abstract}
A B S T R A C T
The concept of fracture for material elements at front of a crack for fatigue crack propagation was extended to the fatigue crack propagation of a cracked metallic member reinforced with a composite patch in this paper. From static mechanics and linear elastic fracture mechanics, force transfer on a cracked member through a composite patch was analyzed and a formula connecting the stress intensity factor with crack length was obtained. Thereafter, a fracture model for fatigue crack propagation of a repaired cracked metallic member was proposed. A new expression for the fatigue crack propagation rate has thus been derived. The expression was verified objectively by the test data. It is in good agreement with the test results.
\end{abstract}

Crown Copyright @ 2009 Published by Elsevier Ltd. All rights reserved.

\section{Introduction}

Repair of cracked metallic structures by bonding of a composite patch has been accepted in engineering application and used to extend service life of these components. This approach has already become a standard one in the aircraft industry [1], where most studies have focused on repair of cracked aluminum alloy structures [2-5]. Such applications have also been used in other engineering fields, such as automobile industry and civil engineering [6-8]. Most of the industrial members are subjected to fatigue loading. Therefore, fatigue assessment has been widely applied to check the effectiveness of a composite patch [7-11].

Glass fiber, carbon fiber and boron fiber composite patches are now used to repair cracked metallic structures. They are fixed on the surface of the cracked metallic structure by adhesive, so that three layer structures can be formed, including the cracked metallic structure, the composite patch, the adhesive layer [12]. The three layer technique has become a base of numerical analysis on the cracked structure reinforced with composite patches [5,8,9]. After a cracked structure is repaired, there is force and a force transfer occurs between the cracked structure and the composite patch through the adhesive layer. Under tension loading, the force transfer will produce a sharing force reduction on both sides of a crack due to the bridging effect of a composite patch. The strain energy release rate at the crack tips is highly reduced [5,8], which results in the improvement of the fatigue life of the cracked member. Therefore, the stress intensity factor analyzed by numerical analysis $[8,13,14]$ exhibits an asymptotic behavior as the crack length is increased and its value decreases considerably in comparison with an unbonded cracked member.

Some analytical and experimental researches have investigated the fatigue crack propagation (FCP) behavior of cracked metallic members repaired with a single-sided or double-sided composite patches $[5,8,9,11,14,15]$. The numerical studies for

\footnotetext{
* Corresponding author. Tel.: +86 13519121619; fax: +86 2988383240.

E-mail address: rong.wang@teacher.com (R. Wang).
} 


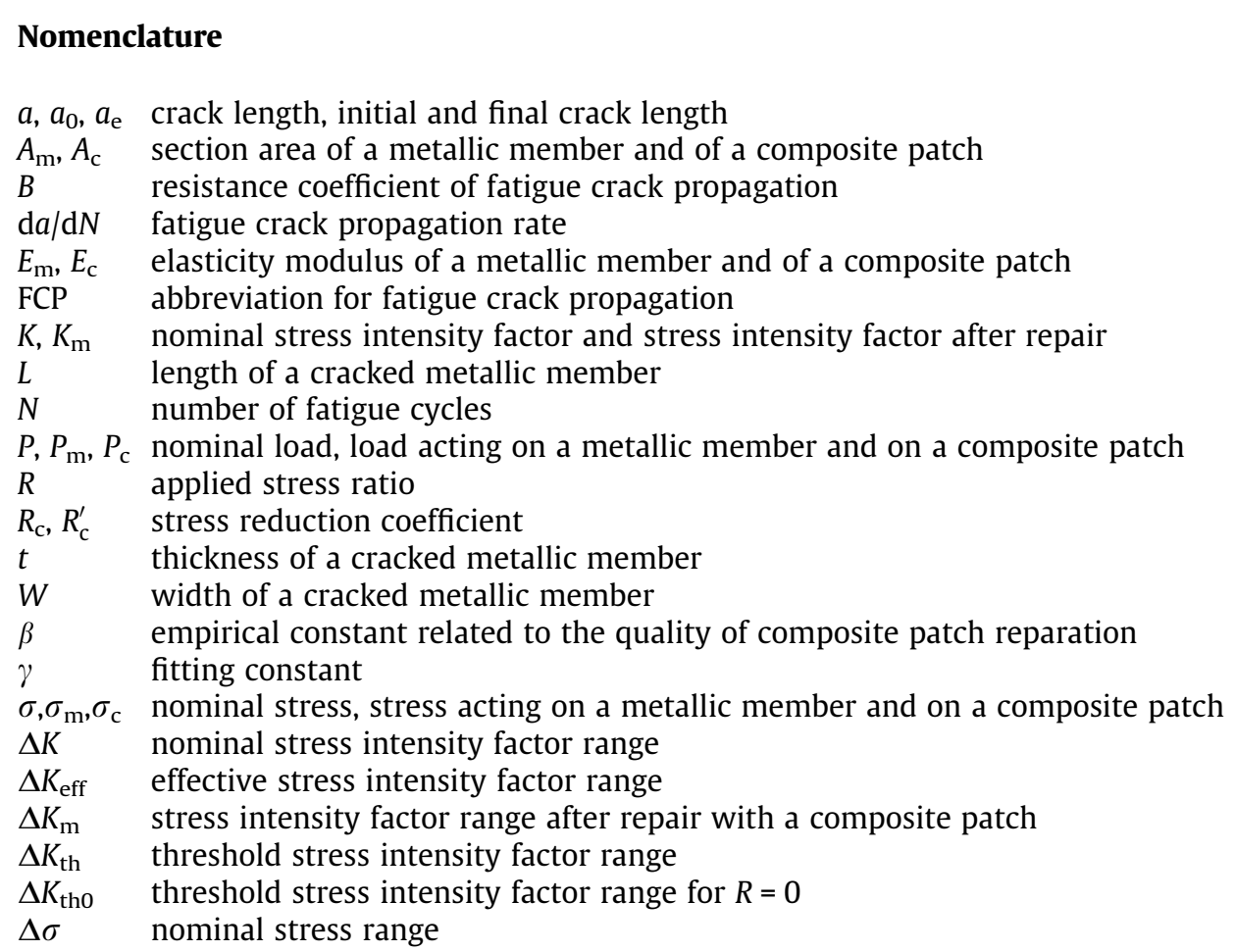

this problem have mainly focused on the determination of stress intensity factors in the cracked panels through calculating the strain energy release rate. Thereafter, Paris equation for the FCP can be used to calculate the $a-N$ curves under fatigue loading $[14,15]$. However, this approach only gives an analytical procedure for the FCP, and does not give a simple expression of the FCP rate for a repaired cracked metallic member.

More recently, a simple methodology for predicting FCP in the low stress intensity factor range region (region I) to mid region (region II, stable crack propagation region) [16] was presented. After examining the FCP history of a range of test specimens and cracks repaired with a composite patch, a nearly linear relationship between the logarithm of the crack length and the number of cycles was proposed. The proportion coefficient in this linear relationship is an empirical parameter, which varies considerably with loading condition, and has no explicit meaning. The shapes of the FCP $a-N$ curves predicted by this methodology are different with those from other test data for the same aluminum alloy $[10,11,17]$.

In this paper, attempts were made to develop a fracture model for FCP of a cracked metallic member reinforced with a composite patch based on the concept of material element fracture in front of a crack tip [18] and the fact that there are no changes in the properties of the metallic member. A FCP rate expression, which reveals the correlation between the FCP rate and intrinsic properties of the metallic member and of the composite patch, the structural configuration of the repaired cracked metallic member, nominal stress intensity factor range, an applied stress ratio, is derived. The FCP rate expression was examined objectively by the test results from literature. Finally, the fracture model and some parameters in the FCP rate expression were discussed.

\section{Modelling fatigue crack propagation of a repaired cracked metallic member}

\subsection{Hypothesis on crack propagation}

FCP in a cracked metallic member reinforced with a composite patch may be assumed to occur when the material elements ahead of a crack tip as illustrated in Fig. 1 [18] are fractured. When a specimen is loaded in tension or the crack is a mode I crack, the fracture of the material elements occurs in a tension fracture known as static fracture [19]. When a specimen is loaded under fatigue loading, the fracture of the material elements occurs in fatigue fracture.

When a composite patch is bonded onto a cracked metallic member, there exists a bridging effect between both sides of the crack. When a load is applied on the cracked metallic member, resulting in an opening displacement of the crack lip, this displacement will be limited by the composite patch, which will then be loaded. Thus there is a force transfer from the metallic element to the composite patch, and the crack opening is reduced. Actual stress applied on the cracked member section, which is different but related to the nominal stress, will be decreased to improve the resistance of the cracked 


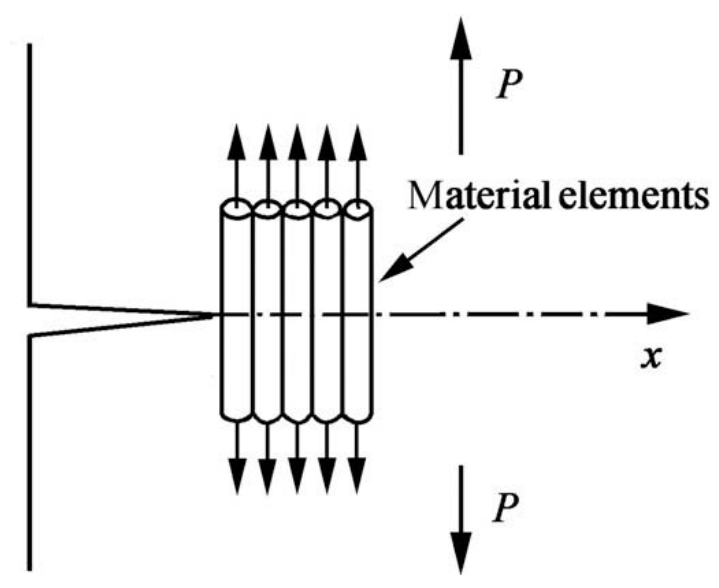

Fig. 1. Illustration of the material elements along the potential crack path [18].

member to fatigue loading and to extend its fatigue life. In other words, a composite patch will cause the stress intensity factor at the tip of the crack of the cracked member to be reduced $[8,13,15]$.

It should be pointed that the intrinsic fatigue properties of the metallic member do not change despite the bonding of the composite patch on the cracked member. This fact has been accounted for in determining stress intensity factor of repaired cracked members either by an experimental approach [9] or by applying Paris equation for FCP analysis [14,15].

\subsection{Fatigue crack propagation rate in metals}

Based on Lal and Weiss [19] static model for crack propagation, Zheng and Hirt [18] proposed a modified static model for FCP in metals. It is based on the assumption that FCP occurs due to the fracture of the so-called fatigue element located ahead of the crack tip as shown in Fig. 1 and that the crack tip must be bluntened during loading in order to maintain the mechanical equilibrium at the crack tip. Considering that the FCP threshold, $\Delta K_{\mathrm{th}}$, always exists and that the difference between stress intensity factor range $\Delta K$ and $\Delta K_{\mathrm{th}}$, which is defined as the effective stress intensity factor range, $\Delta K_{\mathrm{eff}}$, is the governing factor for FCP, a simple expression for the FCP rate in metals, $\frac{\mathrm{d} a}{\mathrm{~d}}$, is derived from the above mentioned model [18]:

$$
\frac{\mathrm{d} a}{\mathrm{~d} N}=B\left(\Delta K-\Delta K_{\mathrm{th}}\right)^{2}
$$

where $B$ is the resistance coefficient of FCP, which is a material constant depending on the tensile properties and the FCP mechanism in the stable crack propagation region.

The test results indicate that the applied stress ratio, $R$, mainly influences the FCP rate near the threshold region. Hence, the threshold $\Delta K_{\text {th }}$ intensively depends on the applied stress ratio. The correlation between $\Delta K_{\text {th }}$ and $R$, obtained by parameter fitting, can be expressed as [20]:

$$
\Delta K_{\mathrm{th}}(R)=\Delta K_{\mathrm{th} 0}(1-R)^{\gamma}
$$

where $\Delta K_{\text {tho }}$ is the threshold for an applied stress ratio $R=0$, and $\gamma$ is a fitting constant ranging between 0 and 1 . Further studies have shown that the expression for the FCP rate well suited to describe the general rules of FCP in steels and aluminum alloys [20,21].

\subsection{Effect of a composite patch}

It is recognized that nominal stress on a cracked metallic member under fatigue loading is less than the yield strength of the structural material; it is under elastic deformation as a whole, except the small scale yielding region at the tip of a crack. It can be assumed that a composite patch bonded onto the cracked metallic member will also undergo elastic deformation under fatigue loading.

According the three layer model [12], a simple two layer structure without the adhesive layer can be taken to consider the force transfer. It is what is done in this paper and shown in Fig. 2. When a nominal load, $P$, corresponding to a nominal stress $\sigma$, is applied on the two layer structure, the structure will experience elastic deformation. The nominal load will be divided into two parts: one is a load $P_{\mathrm{m}}$ that is acting on the metallic member; the other is a load $P_{\mathrm{c}}$ that is acting on the composite patch. Then, a relationship between $P, P_{\mathrm{m}}$ and $P_{\mathrm{c}}$ can be obtained:

$$
P=P_{\mathrm{m}}+P_{\mathrm{c}}
$$




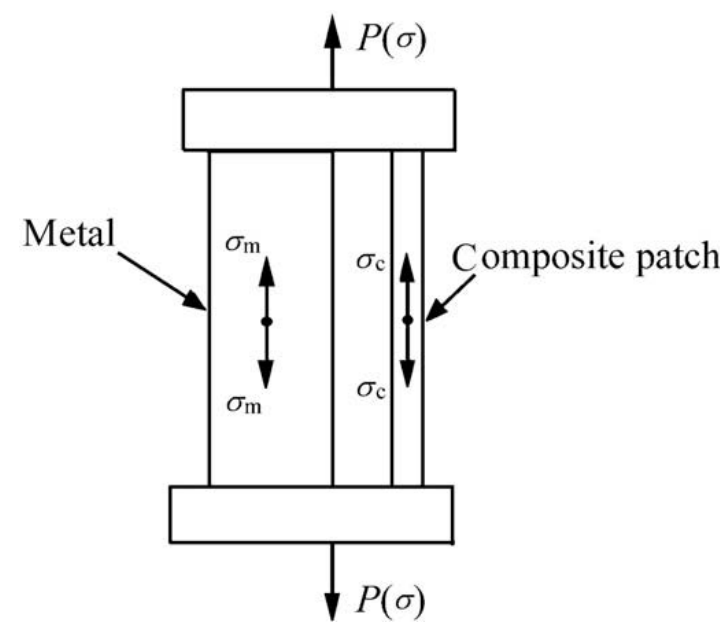

Fig. 2. Illustration of force transfer in a two-layer structure.

Eq. (3) can be expressed in function of stresses:

$$
\sigma\left(A_{\mathrm{m}}+A_{\mathrm{c}}\right)=\sigma_{\mathrm{m}} A_{\mathrm{m}}+\sigma_{\mathrm{c}} A_{\mathrm{c}}
$$

where $A_{\mathrm{m}}$ and $A_{\mathrm{c}}$ are the section area of the metallic member and of the composite patch, and $\sigma_{\mathrm{m}}$ and $\sigma_{\mathrm{c}}$ are the stresses in them, respectively.

Because the metallic member and the composite patch are fixed together at their ends, there will be the same strain, $\varepsilon$, in both of them. From Hooke's law, the relationships between stress and strain are:

$$
\begin{aligned}
& \sigma_{\mathrm{m}}=E_{\mathrm{m}} \varepsilon \\
& \sigma_{\mathrm{c}}=E_{\mathrm{c}} \varepsilon
\end{aligned}
$$

where $E_{\mathrm{m}}$ and $E_{\mathrm{c}}$ are Young's modulus of the metallic member and of the composite patch, respectively.

Substituting Eqs. (5) and (6) into Eq. (4) and removing $\sigma_{\mathrm{c}}$, the stress acting on the metallic member is:

$$
\begin{aligned}
& \sigma_{\mathrm{m}}=R_{\mathrm{c}} \sigma \\
& R_{\mathrm{c}}=\frac{1+A_{\mathrm{c}} / A_{\mathrm{m}}}{1+\left(E_{\mathrm{c}} / E_{\mathrm{m}}\right)\left(A_{\mathrm{c}} / A_{\mathrm{m}}\right)}
\end{aligned}
$$

where $R_{\mathrm{c}}$ may be called the stress reduction coefficient due to the existence of a composite patch.

If both faces of the metallic member are bonded with composite patches, Eq. (8) will become:

$$
R_{\mathrm{c}}=\frac{1+2 A_{\mathrm{c}} / A_{\mathrm{m}}}{1+\left(E_{\mathrm{c}} / E_{\mathrm{m}}\right)\left(2 A_{\mathrm{c}} / A_{\mathrm{m}}\right)}
$$

It can be seen from Eqs. (8) and (9) that $R_{\mathrm{c}}$ is a parameter that combines structural configuration and material properties. For a given metallic member and given composite patches, $R_{\mathrm{c}}$ should be kept constant. Therefore, the stress acting on the metallic member will be decreased and will be less than the nominal stress when composite patches are bonded on it. If $A_{\mathrm{m}} \gg A_{c}$ and $E_{\mathrm{m}}>E_{\mathrm{c}}, R_{\mathrm{c}}$ will be close to a unit and this stress reduction effect, caused by composite patches, will be negligible. This implies that there is little reinforcing effect when composite patches are bonded onto an undamaged metallic member.

In Fig. 3, a cracked metallic member reinforced with composite patches on both faces is considered. A central cracked tension (CCT) specimen with width of $W$ and crack length of $2 a$ is selected. From linear elastic fracture mechanics [22], stress intensity factor at the tip of the crack, $K$, can be expressed as a function of nominal stress:

$$
K=\sigma \sqrt{\pi a} f\left(\frac{2 a}{W}\right)
$$

Substituting Eq. (10) into Eq. (7), the stress intensity factor of the cracked metallic member bonded with composite patches, $K_{\mathrm{m}}$, can be expressed as:

$$
K_{\mathrm{m}}=R_{\mathrm{c}} K
$$

Eq. (11) represents an extreme state, in which the whole section of the composite patches is used to transfer the force or, in other words, the displacement is assumed also to exist on the remaining uncrack section , $W-2 a$, ahead of the crack tips. In reality, the patch section within the part of $W-2 a$ of the cracked metallic member does not transfer any stress without considering the plastic zone at the crack tip. 


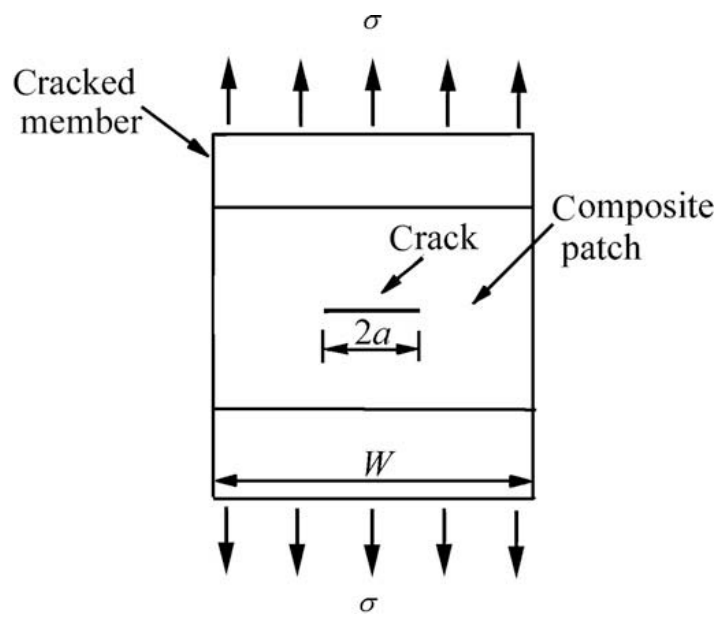

Fig. 3. Force transfer in a reinforced cracked metallic member.

When the crack length is very small or no load is applied on the cracked metallic member, the patches will not transfer any stress. Thus, $K_{\mathrm{m}}$ should approach to $K$. When the length of the crack, $2 a$, is very long and reaches to $W$, assuming that the cracked metallic member would not be fractured, $K_{\mathrm{m}}$ should be equal to the value expressed by Eq. (11). This is equivalent to the case shown in Fig. 2. Applying the principle of average distribution of stress, $K_{\mathrm{m}}$ of the repaired cracked metallic member with a crack length equal to $2 a$ can be express as:

$$
K_{\mathrm{m}}=K\left(1-R_{\mathrm{c}} \frac{2 a}{W}\right)
$$

Under fatigue loading, stress intensity factor $K$ in Eq. (12) should be replaced by stress intensity factor range, $\Delta K$. We then can write:

$$
\Delta K_{\mathrm{m}}=\Delta K\left(1-R_{\mathrm{c}} \frac{2 a}{W}\right)
$$

From Eq. (13), the importance of the reduction of $\Delta K_{\mathrm{m}}$ becomes larger as the crack length is increased. In other words, the reinforcing effect of the composite patches bonded onto a cracked metallic member becomes stronger than onto an undamaged metallic member.

Considering practical bonding technology and its variability, the ideal case illustrated in Fig. 2 can not be reached for all combinations between a cracked metallic member and composite patches. Furthermore, in fatigue test data, one can observe a large variability in specimens with the same patches, adhesive, bonding procedure and tests under the same conditions. An empirical coefficient, $\beta$, is suggested here to take into account the quality of the bonding and its variability. The upper limit $\beta$ is one. Considering the practical bonding quality and variability, the modified stress reduction coefficient $R_{c}^{\prime}$, is expressed as:

$$
R_{\mathrm{c}}^{\prime}=\beta R_{\mathrm{c}}
$$

Then, the expression for $\Delta K_{\mathrm{m}}$, in Eq. (13), can be rewritten as follows:

$$
\Delta K_{\mathrm{m}}=\Delta K\left(1-\beta R_{\mathrm{c}} \frac{2 a}{W}\right)
$$

\subsection{A new FCP rate expression for a repaired cracked metallic member}

It was shown that the stress intensity factor range at the tip of a crack is a main controlling factor for the FCP of a cracked metallic member reinforced with composite patches and that the fatigue property parameters, $B, \Delta K_{\text {tho }}$ and $\gamma$ cannot be changed in the presence of composite patches. Therefore, by substituting $\Delta K_{\mathrm{m}}$, Eq. (15), into Eq. (1) instead of $\Delta K$, a new FCP rate expression for a cracked metallic member reinforced by composite patches is obtained:

$$
\frac{\mathrm{d} a}{\mathrm{~d} N}=B\left[\left(1-\beta R_{\mathrm{c}} \frac{2 a}{W}\right) \Delta K-\Delta K_{\mathrm{th}}\right]^{2}
$$

This expression reveals the correlation between the FCP rate and intrinsic properties of the metallic member and of composite patches, structural configuration of the repaired cracked metallic member, nominal stress intensity factor range. Furthermore, the influence of the applied stress ratio can be taken into account using Eq. (2). 


\section{Verification of the developed model for FCP}

\subsection{Methods}

Tests on cracked aluminum alloy and steel members found in literature $[11,23]$ were used to objectively check and validate the new FCP rate expression proposed in Eq. (16). The procedure for verification is as follows:

(1) The values of $B$ and $\Delta K_{\text {th }}$ for FCP are obtained first. To consider the thickness effect on FCP [24], the data of the fatigue tests without patches are used to get the value of $B$. The value of $\Delta K_{\text {th }}$ is obtained by using Eq. (2) and the applied stress ratio. Step (5) is then used to determine the value of $B$ through a trial and error approach, which ends when the relative error between the test life and the calculated life in fatigue is less or equal to $1 \%$.

(2) The value of $R_{\mathrm{c}}$ is calculated from the structural configuration of the cracked metallic member and composite patches, and their Young's modulus according to Eq. (8) or Eq. (9).

(3) The value of $\beta$, which is considered for each repaired cracked metallic member as a constant related to the quality and variability in the composite patch reparation, can be determined by the fatigue life data. The determining approach is the same as the one for determining the value of $B$.

(4) The values of the parameters $B, \Delta K_{\mathrm{th}}, R_{\mathrm{c}}$ and $\beta$ are introduced into Eq. (16) to get the general FCP rate expression for the cracked metallic member reinforced with composite patches.

(5) The curve of crack length vs. number of fatigue cycles is obtained by numerical integral of the FCP rate:

$N_{\mathrm{f}}=\int_{a_{0}}^{a_{\mathrm{e}}} \frac{1}{(\mathrm{~d} a / \mathrm{d} N)} \mathrm{d} a$

where $N_{\mathrm{f}}$ is the FCP life from a crack length of $a_{0}$ to that of $a_{\mathrm{e}}$. Then comparison can be made between the $a-N$ curve obtained from the developed model and the curve from the fatigue tests, so as to verify if the new FCP rate expression of a cracked metallic member reinforced by composite patches is valid.

As mentioned above, the methods of substantiation by using fatigue life data are a fitting approach. So, the results obtained from the methods are called as a fitting result.

\subsection{Repaired cracked 2024-T3 aluminum alloy members}

In Ref. [11], cracked 2024-T3 aluminum alloy members with a CCT geometry and nominal thickness of $t=2.29 \mathrm{~mm}$ and $t=6.35 \mathrm{~mm}$, reinforced with a glass/epoxy composite patch, were investigated. The typical geometry and loading of such a specimen are shown in Fig. 4. The patch consisted in a single-side patch with 4 layers, 8 layers and 16 layers. Dimensions and material properties of the cracked aluminum alloy panel, adhesive, and composite patch are given in Table 1.

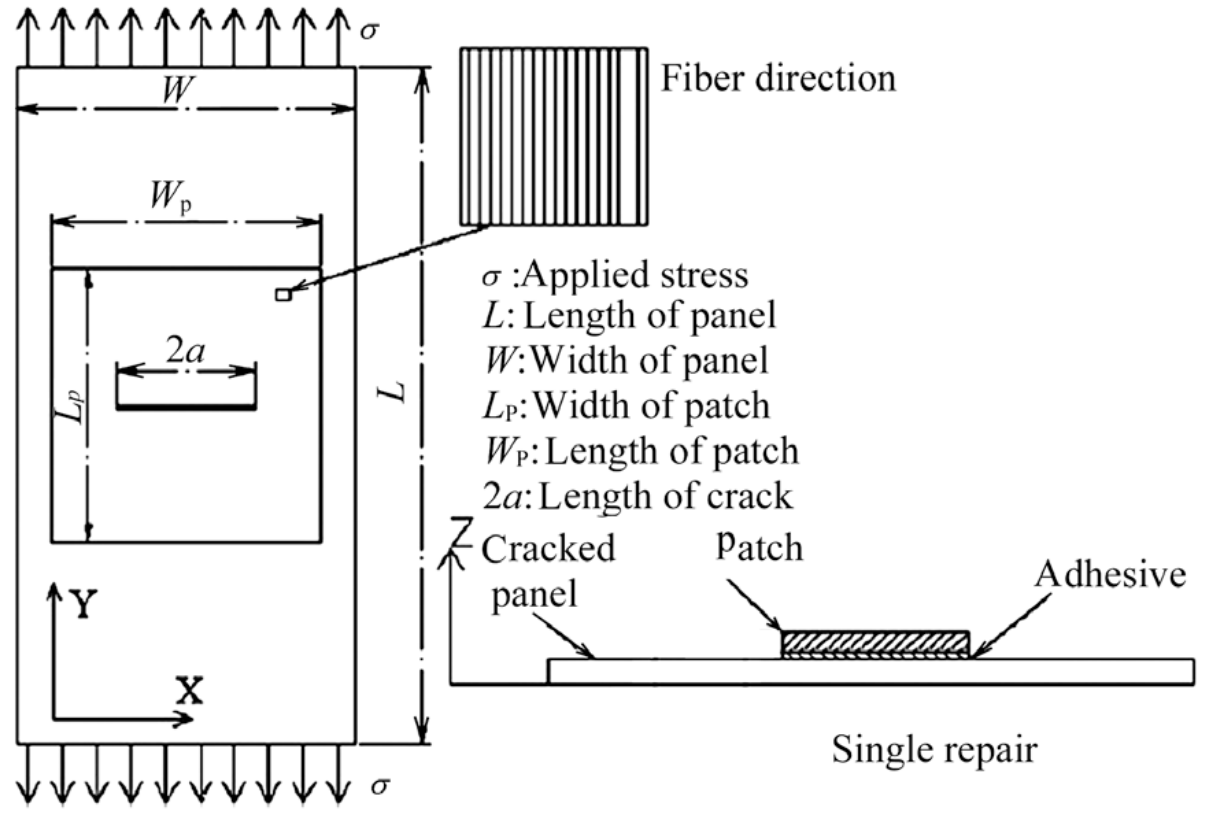

Fig. 4. Typical geometry and loading of single-side repaired panel [11]. 
Table 1

Dimensions and material properties of 2024-T3 reinforced aluminum alloy members [11].

\begin{tabular}{llll}
\hline Layer & $L(\mathrm{~mm})$ & $W(\mathrm{~mm})$ & $t(\mathrm{~mm})$ \\
\hline Aluminum panel & 100 & 50 & 2.29 and 6.53 \\
Patch & 40 & 35 & 0.18 per layer \\
Adhesive & 40 & 35 & 0.1 \\
\hline
\end{tabular}

Constant amplitude cyclic loading was applied at ambient temperature to both un-repaired and repaired specimens with a frequency of $10 \mathrm{~Hz}$, a stress ratio of $R=0.05$ and a maximum applied remote stress of $118 \mathrm{MPa}$. The initial crack length of $2 a$ was equal to $10 \mathrm{~mm}$.

The value of $\Delta K_{\mathrm{th}}$ for 2024-T3 aluminum alloy can be taken from Ref. [25] as 3.1 MPa $\sqrt{\mathrm{m}}$ corrected for $R=0.05$ using Eq. (2). The other parameters are determined following the procedure given in Section 3.1. The results are listed in Table 2.

Substituting the parameters in Table 2 into Eq. (16), the general expressions for FCP rates for the cracked 2024-T3 aluminum alloy members without patch and with a patch at $R=0.05$ can be obtained, for example:

For the cracked member with $t=2.29 \mathrm{~mm}$ and without patch:

$$
\frac{\mathrm{d} a}{\mathrm{~d} N}=9.69 \times 10^{-10}(\Delta K-3.1)^{2}
$$

For the cracked member with $t=2.29 \mathrm{~mm}$ and a 4 layer patch:

$$
\frac{\mathrm{d} a}{\mathrm{~d} N}=9.69 \times 10^{-10}\left[\left(1-2.956 \times 10^{-2} a\right) \Delta K-3.1\right]^{2}
$$

and so on.

These expressions are then used to get the fitting $a-N$ curves by using Eq. (17). The curves of $a-N$ are drawn onto the test data figures from Ref. [11], as shown in Fig. 5. It can be seen that the fitting $a-N$ curves for the cases with patches are in fairly good agreement with the test data.

\subsection{Repaired cracked steel members}

In Ref. [23], cracked Fe E 235-C steel members with a CCT geometry and a nominal thickness of $t=10 \mathrm{~mm}$ reinforced with carbon fiber polymer patches were investigated, as shown in Fig. 6. Patches on both steel member faces with a nominal thickness of $1.2 \mathrm{~mm}$ were bonded onto the cracked member. Dimensions and material properties of the cracked steel member, adhesive, and composite patches are given in Table 3.

Constant amplitude cyclic loading was applied to both un-repaired and repaired members with a stress ratio of $R=0.4$ and an applied remote nominal stress range of $\Delta \sigma=80 \mathrm{MPa}$. The initial crack length $2 a$, hole included, was equal to 30 mm.

As mentioned in Section 2.2, the applied stress ratio has an apparent effect on $\Delta K_{\mathrm{th}}$. When $R \leq 0.4$, the correlation between $\Delta K_{\text {th }}$ and $R$ for low carbon steels [20] can be approximated by the following expression:

$$
\Delta K_{\text {th }}=10.1(1-R)
$$

Thus, the value of $\Delta K_{\mathrm{th}}$ for Fe E 235-C steel is taken as 6.06 for $R=0.4$ from Eq. (20). The other parameters are determined following the procedure given in Section 3.1. The results are listed in Table 4.

Substituting the parameters in Table 4 into Eq. (16), the general expressions for FCP rates of the cracked steel members without patch and with patches at $R=0.4$ can be obtained:

For the cracked member without patch:

$$
\frac{\mathrm{d} a}{\mathrm{~d} N}=1.95 \times 10^{-10}(\Delta K-6.06)^{2}
$$

\begin{tabular}{|c|c|c|c|c|c|}
\hline$t(\mathrm{~mm})$ & $B(\mathrm{MPa})^{-2}$ & $\Delta K_{\mathrm{th}}(\mathrm{MPa} \sqrt{\mathrm{m}})$ & $R_{\mathrm{c}}$ & $\beta$ & Patch \\
\hline 2.29 & $9.69 \times 10^{-10}$ & 3.1 & $\begin{array}{l}- \\
1.071 \\
1.117 \\
1.180\end{array}$ & $\begin{array}{l}- \\
0.690 \\
0.750 \\
1.000\end{array}$ & $\begin{array}{l}\text { No } \\
4 \text { Layers } \\
8 \text { Layers } \\
16 \text { Layers }\end{array}$ \\
\hline 6.36 & $1.82 \times 10^{-9}$ & 3.1 & $\begin{array}{l}- \\
1.029 \\
1.051 \\
1.089\end{array}$ & $\begin{array}{l}- \\
0.225 \\
0.225 \\
0.225\end{array}$ & $\begin{array}{l}\text { No } \\
4 \text { Layers } \\
8 \text { Layers } \\
16 \text { Layers }\end{array}$ \\
\hline
\end{tabular}

Table 2

Crack propagation parameters for 2024-T3 aluminum alloy members. 

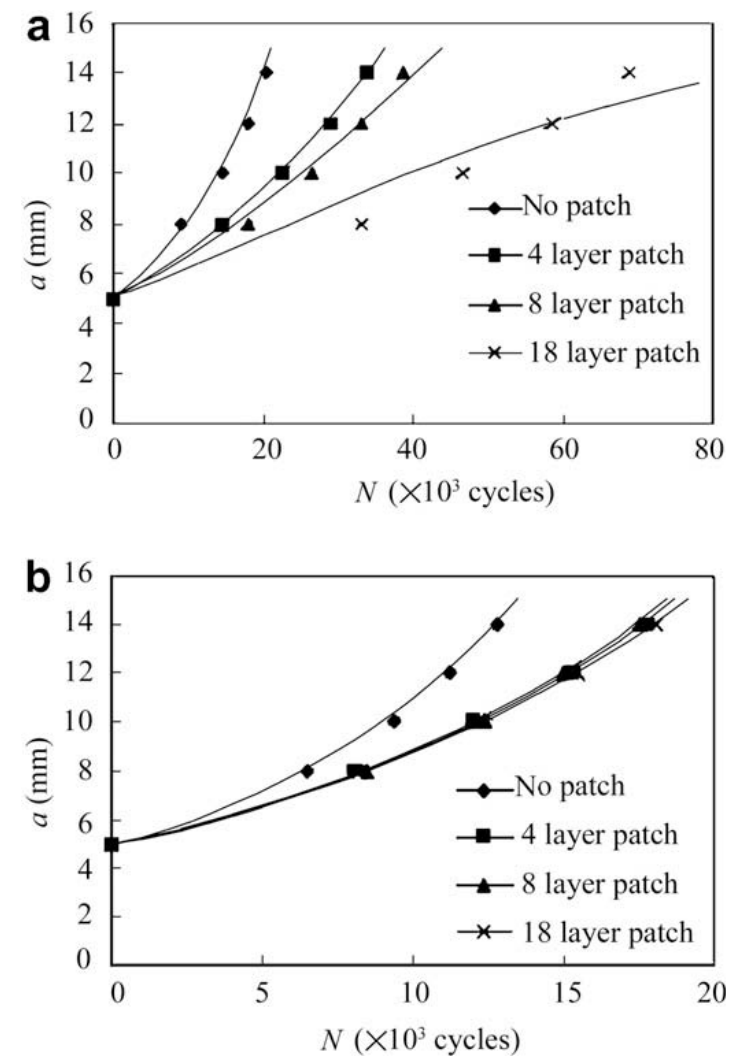

Fig. 5. Comparison between the fitting $a-N$ curves from the model and test data [11]: (a) $t=2.29 \mathrm{~mm}$, (b) $t=6.35 \mathrm{~mm}$.

For the cracked member with patches on both faces:

$\frac{\mathrm{d} a}{\mathrm{~d} N}=1.95 \times 10^{-10}\left[\left(1-6.753 \times 10^{-3} a\right) \Delta K-6.06\right]^{2}$

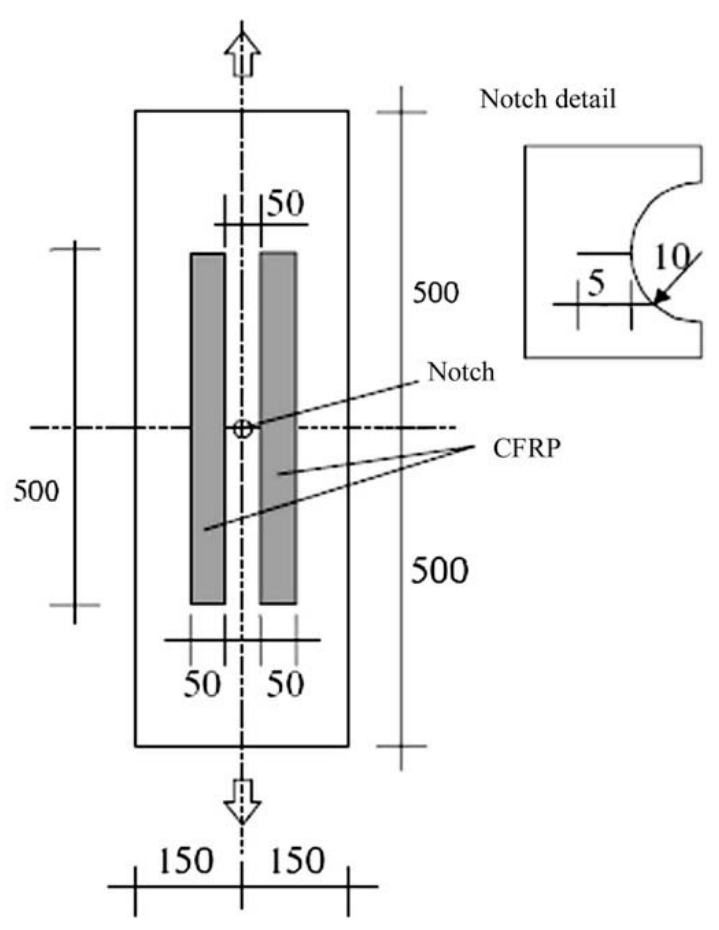

Fig. 6. Notched steel plate specimen [23]. 
Table 3

Dimensions and material properties of the reinforced steel members [23].

\begin{tabular}{lllll}
\hline Layer & $L(\mathrm{~mm})$ & $W(\mathrm{~mm})$ & $t(\mathrm{~mm})$ & 10 \\
\hline Steel panel & 1000 & 300 & 1.2 & $E_{\mathrm{m}}=210$ \\
Patch & - & $2 \times 50$ & $2 \times 50$ & 0.3 \\
Adhesive & - & $2 \times 174$ & - \\
\hline
\end{tabular}

Table 4

Crack propagation parameters for Fe E 235-C steel.

\begin{tabular}{lllll}
\hline$B(\mathrm{MPa})^{-2}$ & $\Delta K_{\mathrm{th}}(\mathrm{MPa} \sqrt{\mathrm{m}})$ & $R_{\mathrm{c}}$ & $\beta$ \\
\hline $1.95 \times 10^{-10}$ & 6.06 & - & - \\
& & 1.013 & Notch \\
Patch
\end{tabular}

These expressions are used to get the fitting $a-N$ curves under the loading conditions of $\Delta \sigma=80 \mathrm{MPa}$ and $R=0.4$ according to Eq. (17) by numerical integral. The fitting curves of $a-N$ are drawn on the test data figure[23], as shown in Fig. 7. The fitting $a-N$ curves are in good agreement with the test data for the cracked steel members. The maximum relative error is within a $\pm 15 \%$ band.

\section{Discussion}

\subsection{On the fracture model}

The modified static fracture model for FCP in metals [18] can well used to properly analyze and predict FCP rates in more than 100 steels and widely-used aluminum alloys[20,21]. It can be applied to the stable crack propagation region and the threshold region with the exception of the unstable crack propagation region (near $K_{\mathrm{IC}}$ ) or when da/d $N$ is less than $10^{-6} \mathrm{~m} /$ cycle. This is of practical importance for engineering applications. When composite patches are bonded onto a cracked metallic member, the reinforcing effect can drastically extend the fatigue life of the member [10,15] and may result in a decrease of the FCP rate into the threshold region [10], in which Paris equation does not be applied.

A general consideration in the researches on this subject $[6,8,9,15]$ is that a composite patch decreases stress intensity factor through the bridging effect on both sides of a crack to extend fatigue life of a cracked metallic member. Thus, the composite patches improve the stress intensity factor level at the tip of a crack and cannot change the fatigue properties of the member material. Gigacycle fatigue tests [10] have proven that the value of $\Delta K_{\text {th }}$ is not altered significantly due to repair. This means that a certain amount of the crack opening displacement is needed to keep the reinforcing effect of the composite patches. From the geometry of a cracked metallic member, the cases of $2 a=0$ and $2 a=W$ are two extreme conditions corresponding to no reinforcing effect and maximum reinforcing effect, respectively. The degree of reinforcing effect should rise as the length of a crack is increased.

\subsection{On the expression for the FCP rate of a repaired cracked metallic member}

It is shown from the fitting results of $a-N$ curves of repaired cracked aluminum alloy and steel members that the expression developed for the FCP rate of a repaired cracked metallic member, given by Eq. (16), is well suited to quantitatively

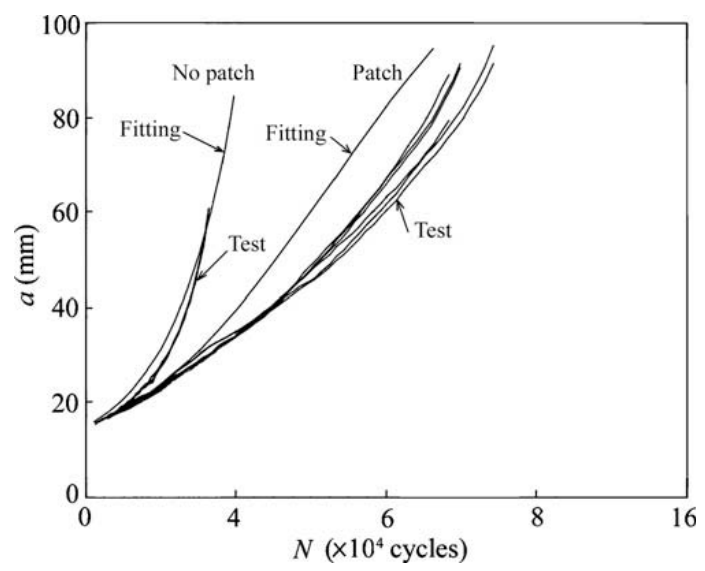

Fig. 7. Comparison between the fitting $a-N$ curves from the developed model and test data [23]. 
analyze the test results. The reason behind it may be that the assumptions used to develop the fracture model for the FCP of repaired cracked members are also reasonable and suitable for the FCP of the repaired cracked metallic member.

The new expression derived in this paper, which reveals the correlation between FCP rate and intrinsic properties of the metallic member and of composite patches, structural configuration of the repaired cracked metallic member, nominal stress intensity factor range, a applied stress ratio, is believed to be a better formula for easily predicting the FCP rate of a repaired cracked metallic member.

It is very interesting to see that the case of $\beta=1$ appears in Tables 2 and 4 . This means that the quality of the bonding can be considered as practically perfect. In these cases, it is very simple to predict the FCP rate only using the material properties $\left(B, \Delta K_{\mathrm{th}}, E_{\mathrm{m}}, E_{\mathrm{c}}\right)$, structural configuration of a repaired cracked member, and fatigue loading $(\Delta \sigma, R)$. More importantly, every parameter in Eq. (16) has an explicit meaning.

\subsection{On the value of $R_{c}$}

$R_{\mathrm{c}}$ is defined as the stress reduction coefficient, which is caused by a composite patch for an undamaged metallic member. $R_{\mathrm{c}}$ is used for a repaired cracked member to describe the relationship between the stress intensity factor and the length of a crack according to the principles of linear elastic fracture mechanics and average distribution of stress. Determination of the stress intensity factor for a repaired cracked member is a key problem in many numerical analyses $[2,8,13,15,17]$.

It can been seen from Eqs. (8) and (9) that the value of $R_{\mathrm{c}}$ is very close to a unit for thick metallic members. Hence, fatigue strength of a cracked metallic member cannot significantly enhanced by increasing the thickness of a composite patch. This has been shown by test results and numerical analysis $[8,11]$.

The parameter $\left(1-R_{\mathrm{c}} \frac{2 a}{W}\right)$ in Eqs. (12) and (13) may be called the reduction function of the stress intensity factor for a repaired cracked metallic member. According to this result, the stress intensity factor of a repaired cracked metallic member will be decreased linearly with the length of a crack as the crack length is increased. Recently, numerical analyses of cracked aluminum alloy members with patches and patches + stiffeners has also proven a linear variation of the stress intensity factor with crack length [26].

A good agreement between the fitting $a-N$ curves by using Eq. (16) and test data for repaired cracked aluminum alloy and steel members in Figs. 5 and 7 is a strong support to the developed stress intensity factor reduction parameter for the repaired cracked metallic members, especially for the cases where $\beta=1$.

\subsection{On the empirical coefficient $\beta$}

$\beta$ is an empirical coefficient for reflecting the quality variability of practical bonding technology. For each specimen, the value of $\beta$ should be kept constant. The value of $\beta$ may be different for different specimens. From the analysis results in Table 2 , the values of $\beta$ vary from 0.225 to 1 for a glass/epoxy composite patch. However, all the $\beta$ values for the repaired steel members with carbon fiber polymer patches ( 6 specimens in total) are identical and equal to one in Table 4 and Fig. 7.

Large differences in fatigue test lives for different specimens with the same repair technology have been seen [17]. It should be pointed out that these large differences in fatigue test life data often appears for cracked members with a single side patch. Consequently, it is effectively necessary to take the quality difference of practical bonding technology into account through this empirical coefficient.

\section{Conclusions}

Based on the concept of fracture for material elements at the front of a crack for FCP proposed by Zheng and Hirt, a fracture model for a repaired cracked metallic member is developed in this paper. The following preliminary conclusions could be drawn:

(1) FCP of a cracked metallic member reinforced with composite patches occurs due to the fracture of the so-called fatigue element located ahead of the crack tip. Composite patches result in a decrease of the stress intensity factor through the bridging effect on both sides of a crack. The fatigue properties of the cracked member material cannot be changed.

(2) According to the principles of static mechanics and linear elastic fracture mechanics, a stress reduction coefficient is suggested. A reduction parameter of stress intensity factor for a repaired cracked metallic member is proposed. The stress intensity factor of a repaired cracked metallic member is decreased in a linear relationship with the length of a crack as crack length is increased.

(3) Based on the fracture model, a new expression for the FCP rate for a repaired cracked metallic member, which reveals the correlation between the FCP rate and intrinsic properties of a metallic member and of a composite patch, the structural configuration of a repaired cracked metallic member, nominal stress intensity factor range, an applied stress ratio, is derived for CCT specimens as follows: $\frac{\mathrm{d} a}{\mathrm{~d} N}=B\left[\left(1-\beta R_{\mathrm{c}} \frac{2 a}{W}\right) \Delta K-\Delta K_{\mathrm{th}}\right]^{2}$ where $B$ is the resistance coefficient for FCP, $\Delta K_{\mathrm{th}}$ is the threshold, $R_{\mathrm{c}}$ is a stress reduction coefficient, $\beta$ is an empirical coefficient, $a$ is crack length and $W$ is width of CCT specimens. 
(4) The new expression is verified objectively by comparisons with test data on cracked aluminum alloy members with a composite patch and on cracked steel members with composite patches taken from literature. It shows a fairly good agreement with the test data. The new expression can provide a simple engineering means to analyze the FCP rule and predict fatigue life of cracked metallic members, which are repaired with adhesively bonded composite patches.

\section{Acknowledgements}

The first author is a visiting scholar at ICOM, Swiss Federal Institute of Technology Lausanne, supported by China Scholarship Council. We are grateful to Prof. Hirt, Dr. Lebet and other staff members of ICOM for their help and support.

\section{References}

[1] Baker AA, Jones R. Bonded repair of aircraft structures. Martinus Nijhoff Publisher; 1988.

[2] Fekirini H, Bouiadjra BB, Belhouari M, Boutabout B, Serier B. Numerical analysis of the performances of bonded composite repair with two adhesive bands in aircraft structures. Compos Struct 2008;82:84-9.

[3] Hosseini-Toudeshky H. Effects of composite patches on fatigue crack propagation of single-side repaired aluminum panels. Compos Struct 2006;76:243-51.

[4] Chung K-H, Yang W-H. A study on the fatigue crack growth behavior of thick aluminum panels repaired with a composite patch. Compos Struct 2003;60:1-7.

[5] Bouiadjra BB, Fekirini H, Belhouari M, Boutabout B, Serier B. Fracture energy for repaired cracks with bonded composite patch having two adhesive bands in aircraft structures. Comput Mater Sci 2007;40:20-6.

[6] Meier U. Carbon fiber-reinforced polymers: modern materials in bridge. Struct Engng Int 1992;2(1):7-12.

[7] Colombi P, Bassetti A, Nussbaumer A. Delamination effects on cracked steel members reinforced by prestressed composite patch. Theor Appl Fract Mech 2003;39:61-71.

[8] Colombi P, Bassetti A, Nussbaumer A. Analysis of cracked steel members reinforced by pre-stress composite patch. Fatigue Fract Engng Mater Struct 2003;26(5):9-66.

[9] Naboulsi S, Mall S. Characterization of fatigue crack aluminium panels with a bonded patch. Compos Struct 1997;37(3/4):321-34.

[10] Wang QY, Sriraman MR, Kawagoishi N, Chen Q. Fatigue crack growth of bonded composite repairs in gigacycle regime. Int J Fatigue 2006;28:1197-201.

[11] Hosseini-Toudeshky H, Mohammadi B, Sadeghi G, Daghyani HR. Numerical and experimental fatigue crack growth analysis in mode-I for repaired aluminum panels using composite material. Composites 2007;A38:1141-8.

[12] Naboulsi S, Mall S. Modeling of a cracked metallic structure with bonded composite patch using the three layer technique. Compos Struct 1996;35:295-308.

[13] Ayatollahi MR, Hashemi R. Computation of stress intensity factors $\left(\mathrm{K}_{\mathrm{I}}, \mathrm{K}_{\mathrm{II}}\right)$ and $\mathrm{T}$-stress for cracks reinforced by composite patching. Compos Struct 2007;78:602-9.

[14] Hosseini-Toudeshky H, Mohammadi B. A simple method to calculate the crack growth life of adhesively repaired aluminum panels. Compos Struct 2007;79:234-41.

[15] Sekine H, Yan B, Yasuho T. Numerical simulation study of fatigue crack growth behavior of cracked aluminum panels repaired with a FRP composite patch using combined BEM/FEM. Engng Fract Mech 2005;72:2549-63.

[16] Jones R, Krishnapillai K, Pitt S. Crack patching: predicting fatigue crack growth. Theor Appl Fract Mech 2006;45:79-91.

[17] Seo D-C, Lee J-J. Fatigue crack growth behavior of cracked aluminum plate repaired with composite patch. Compos Struct 2002;57:323-30.

[18] Zheng XL, Hirt MA. Fatigue crack propagation in steels. Engng Fract Mech 1983;18(5):965-73.

[19] Lal DN, Weiss V. Notch analysis of fracture approach to fatigue crack propagation. Metall Trans 1978;9A(3):326-413.

[20] Zheng XL. A simple formula for fatigue crack propagation and a new method for the determination of $\Delta K_{\text {th. }}$ Engng Fract Mech $1987 ; 27(4): 465-75$.

[21] Li Z. Estimation of fatigue crack propagation rate in steel. Engng Fract Mech 1994;48(3):339-45.

[22] Suresh S. Fatigue of materials. Chambridge: Chambridge University Press; 1991.

[23] Colombi P. Plasticity induced fatigue crack growth retardation model for steel elements reinforced by composite patch. Theor Appl Fract Mech 2005;43:63-76.

[24] Holper B, Mayer H, Vasudevan AK, Stanzl-Tschegg SE. Near threshold fatigue crack growth in aluminium alloys at low and ultrasonic frequency: influences of specimen thickness, strain rate, slip behaviour and air humidity. Int J Fatigue 2003;25:397-411.

[25] Li X-D. Dislocation pile-up model of fatigue thresholds for 2024-and 7075-alike aluminum alloys. Theor Appl Fract Mech 1996;24:165-79.

[26] Sabelkin V, Mall S, Avram JB. Fatigue crack growth analysis of stiffened cracked panel repaired with bonded composite patch. Engng Fract Mech 2006;73:1553-67. 